American Journal of Pharmaceutical Education 2020; 84 (7) Article 7939.

\title{
COMMENTARY
}

\section{The Importance of Vulnerability in Pharmacy Educators}

\author{
Timothy J. Bloom, $\mathrm{PhD}^{\mathrm{a}, \mathrm{b}}$ \\ ${ }^{a}$ Shenandoah University, Bernard J. Dunn School of Pharmacy, Winchester, Virginia \\ ${ }^{\mathrm{b}}$ Editorial Board Member, American Journal of Pharmaceutical Education, Arlington, Virginia
}

Submitted November 20, 2019; accepted January 7, 2020; published July 2020.

Keywords: behavior, emotional intelligence

In an article in Faculty Focus, an online newsletter for those working in higher education, Dr. LynnAnne Lowrie, a faculty member who teaches psychology and counseling, wrote about the benefits of faculty vulnerability in the teaching environment. ${ }^{1}$ She was inspired by her own concerns as a young teacher about whether being vulnerable had a negative impact on teacher credibility, and describes her attempts to hide any weakness or deficiency from her students so they would have greater confidence in her expertise. Lowry kept her students at arm's length to make it more difficult for them to see the struggles she was having while learning to be a teacher. Only after several years of teaching did she listen to advice from older colleagues and began to make herself more vulnerable with her students. That change not only removed the burden of hiding herself from her students, she believed it increased the learning that took place in her classroom.

In support of her change toward being more open, Lowrie points to research that indicates interpersonal relationships with a teacher may be as important for motivating student learning as the content provided by the teacher. Research on student feedback emphasizes the importance of faculty interaction, and trust in the teacher has been discussed as important for transformational learning. ${ }^{2,3}$ Brene Brown argues that vulnerability is essential for developing trust in a relationship. ${ }^{4}$ Brown says that vulnerability includes letting people see you are not perfect, that you make mistakes, and that you do not know everything. Being vulnerable is a step in showing people that you are worthy of trust because you are trusting them with information that could be potentially embarrassing for you.

As a pharmacy educator, I agree with Lowry that good teaching requires vulnerability, in part because the options for avoiding vulnerability are limited for a teacher

Corresponding Author: Timothy J. Bloom, Shenandoah University, Bernard J. Dunn School of Pharmacy, 1775 N Sector Ct., Winchester, VA 22601. Tel: 540-678-4395. Email: tbloom2@su.edu compared to many other professions. For example, professional athletes do their practicing out of the spotlight; thus, their peers see the mistakes that are part of improvement, but fans only see the end product of many hours of practice. In contrast, teachers make their mistakes in front of the people they are trying to help while simultaneously trying to maintain an appearance of credibility and expertise.

Being vulnerable does not mean sharing all of your secrets with students. For example, we demonstrate vulnerability when we recruit students to do research. Asking a research question is clearly an example of admitting a lack of knowledge, but more importantly it demonstrates an area of interest. We are saying to the student, "This is of interest to me. Others may find it boring but I think it is interesting and therefore I am sharing that with you. I am making myself vulnerable."

Something as simple as demonstrating your sense of humor can be a display of vulnerability because humor is so subjective (ask anyone accused of telling "dad jokes"). Students often respond well to teachers who are able to acknowledge their mistakes and make a little bit of fun of themselves. Sharing a mildly embarrassing but humorous story to illustrate a teaching point is an example of vulnerability that I often use in teaching and relating to pharmacy students. In my current administrative role within a school of pharmacy, I feel it is particularly important for students to see that I have a sense of humor and am willing to share a bit of myself with them.

If you are fortunate with your teaching assignment, you will be covering topics about which you are passionate, maybe even those that motivated you to become a graduate or professional student yourself. Sharing that passion opens you up to negative feedback from those who feel differently about the topic or, worse, cannot see how it is relevant. While working on faculty promotion and tenure committees, or serving as an outside reviewer on promotion dossiers, I have noticed many positive student evaluation comments related to the passion the teacher demonstrated for the subject matter. There may be 


\section{American Journal of Pharmaceutical Education 2020; 84 (7) Article 7939.}

several reasons why students appreciate this passion. It may make the presentation of the material more interesting, which makes paying attention easier. It might also be an unconscious recognition of the teacher being vulnerable and therefore more connected with the students.

Every semester brings one more opportunity to feel vulnerable: student evaluations. How often are new faculty members advised to have a stiff drink handy as they go through their end-of-course evaluations? One way to approach this stressful situation is to make clear to the students that you will take their constructive criticisms to heart and consider their suggestions for making improvements. You do not have to wait for the end of the semester to prepare students for this; instead, ask for feedback during the semester and then make some of the suggested changes. For a number of years, I have taught courses that require a lot of student writing. This places demands on the students as well as myself, so as I learned how to run a writing-intensive class, I would regularly ask students what was causing them problems with the assignments. Some suggestions were easy to address, such as being asked to use the comments and track changes features in Microsoft Word to give feedback rather than writing notes on a hard copy, since my handwriting is poor at best. Regardless of whether a change was difficult or easy, students told me that my willingness to acknowledge my way may not have been the best way was evidence that I cared about their learning.

Students also deal with vulnerability issues in the classroom. They can be convinced that there is one right answer to every problem and that their worth is demonstrated by their ability to find that one answer. In my experience, students are less likely to participate in class when they do not feel secure in what they are being asked to do and when they feel they will be called out for making mistakes. This is a problem as they are typically encountering new material that they must mentally connect to what they already know or believe. Many students are very aware of what they do not know about their coursework or what they have forgotten from previous courses, and may feel ashamed as a result.

Brene Brown writes that feelings of shame or trying to avoid shame often leads to perfectionism. Brown's research shows that vulnerability and trust help minimize shame's effects and reduce the need for defenses like perfectionism. ${ }^{4}$ It is important for students to recognize that expertise develops over time and takes lots of practice, and practice involves making mistakes. However, if we make ourselves vulnerable and acknowledge that we still make mistakes after years of experience, it will be easier for students to accept that they cannot expect to be perfect.

I assert that the willingness to be vulnerable is even more important in the pharmacy classroom than in the typical undergraduate classroom. The 2013 Center for the Advancement of Pharmacy Education outcomes list several roles pharmacists play that are relationship-based. ${ }^{6}$ Educator, caregiver, advocate, collaborator, includer, communicator, and leader all require interpersonal relationships and therefore require developing trust with others. By using approaches to develop a professional interpersonal relationship with our students, we are modeling behaviors that they can apply during advanced pharmacy practice experiences, a residency, and their first job as a practitioner. If Brown is correct, we are helping student pharmacists improve their ability to fill these roles when we demonstrate vulnerability and encourage them to do the same.

A simple way to demonstrate vulnerability is to acknowledge our humanness. We have likes and dislikes, and there are things that please us or make us angry. Although we have ways we like to do things, we are open to discussing other approaches, engaging in conversation, and exchanging ideas. We are willing to listen to others because we know we may not have the perfect answer. Students see us being vulnerable when we demonstrate listening to and acknowledging others' ideas because we accept that they may be better than our own. By demonstrating to our students that we do not have all the answers or that we may disagree with our peers on the answers to complex problems, we encourage them to allow their own imperfections.

\section{REFERENCES}

1. Lowrie L. Vulnerability in the classroom. Faculty Focus. 2019. https://www.facultyfocus.com/articles/teaching-and-learning/ vulnerability-in-the-classroom/. Accessed July 13, 2020.

2. Vaughn LM, Baker RC. Psychological size and distance: emphasizing the interpersonal relationship as a pathway to optimal teaching and learning conditions. Med Educ. 2004;38(10): 1053-1060.

3. Yair G. Can we administer the scholarship of teaching? Lessons from outstanding professors in higher education. High Educ. 2008;55(4):447-459.

4. Brown B. Daring Greatly: How the Courage to be Vulnerable Transforms the Way We Live, Love, Parent, and Lead. New York, NY: Penguin; 2015.

5. Dweck C. Mindset: The New Psychology of Success. New York, NY: Ballantine Books; 2016.

6. Medina MS, Plaza CM, Stowe CD, et al. Center for the

Advancement of Pharmacy Education 2013 educational outcomes. Am J Pharm Educ. 2013;77(8):Article 162. 